\title{
The Plausibility of Lowe's Metaphilosophy
}

\section{Document Version}

Accepted author manuscript

Link to publication record in Manchester Research Explorer

\section{Citation for published version (APA):}

Daly, C. (Accepted/In press). The Plausibility of Lowe's Metaphilosophy. In Jonathan Lowe and Ontology Routledge.

\section{Published in:}

Jonathan Lowe and Ontology

\section{Citing this paper}

Please note that where the full-text provided on Manchester Research Explorer is the Author Accepted Manuscript or Proof version this may differ from the final Published version. If citing, it is advised that you check and use the publisher's definitive version.

\section{General rights}

Copyright and moral rights for the publications made accessible in the Research Explorer are retained by the authors and/or other copyright owners and it is a condition of accessing publications that users recognise and abide by the legal requirements associated with these rights.

\section{Takedown policy}

If you believe that this document breaches copyright please refer to the University of Manchester's Takedown Procedures [http://man.ac.uk/04Y6Bo] or contact uml.scholarlycommunications@manchester.ac.uk providing relevant details, so we can investigate your claim.

\section{OPEN ACCESS}


Jonathan Lowe and Ontology 



\section{Jonathan Lowe and Ontology}

Edited by

Mirosław Szatkowski 
Library of Congress Cataloging-in-Publication Data

A CIP catalog record for this book has been applied for at the Library of Congress.

Bibliographic information published by the Deutsche Nationalbibliothek

The Deutsche Nationalbibliothek lists this publication in the Deutsche Nationalbibliografie; detailed bibliographic data are available in the Internet at http://dnb.dnb.de.

(C) 2020 Walter de Gruyter GmbH, Berlin/Boston

(2) Printed on acid-free paper

Printed in Germany

www.degruyter.com 


\section{Contents}

Chris Daly

The Plausibility of Lowe's Metaphilosophy - 1

Authors of Contributed Papers -23

Person Index -27 



\section{Chris Daly}

\section{The Plausibility of Lowe's Metaphilosophy}

\section{Lowe and Quine}

Metaphilosophy is about how we do philosophy. Lowe's way of doing philosophy, and specifically of doing metaphysics, is not Quine's. Lowe is forthright:

Quinean 'ontology' is a travesty of the real thing and more of a threat to genuine ontology than anything issuing from the pens of self-professed antirealists and relativists (Lowe (2008), p. 276).

Quine's way has two stages (Quine (1948) and Quine (1960) chapter V). Stage 1: we marshal current scientific theory. Stage 2: we regiment the sentences of those theories in first-order logic. Following stage 2 here is what we say exists: what exists are the values of the variables in the existentially quantified sentences found in our regimentation of scientific theory. So we have what science says - this is to be found in the textbooks and research papers of today's scientists - and we have what philosophical analysis says - this is to be found in how what science says is regimented. And that, for Quine, is all that there is to be said. For Lowe, however, there is more to say. In particular, he thinks that metaphysics, as opposed to the natural sciences or semantics, has something distinctive and important to say. What metaphysics has to say comes in two stages. Stage 1: metaphysics says what is fundamental. Stage 2: metaphysics says, of each fundamental thing, how it is possible.

Here is the agenda for this paper. First, what should we make of Lowe's case against Quine? Second, what should we make of Lowe's claim that metaphysics says what is fundamental? Third, what should we make of Lowe's claim that metaphysics says, of each fundamental thing, how it is possible? I should say in advance that my answers are critical of Lowe's claims, but I think Lowe would be the first to say that we make philosophical progress only if we engage closely and rigorously with the views of fellow philosophers. Lowe's views on metaphilosophy are deep, original and reward careful scrutiny.

We begin with the first task: what should we make of Lowe's case against Quine? Lowe denies that science and semantics suffice to answer metaphysical questions - or at least the ones that he is interested in Lowe (1998), p. 3. Let's consider Lowe's case against each of these two disciplines' contribution to metaphysics in turn. 


\section{Lowe's case against science usurping metaphysics}

Lowe argues as follows against science’s suitability (?, p. 5). (1) Scientists make metaphysical assumptions when they propose and test their theories. (2) Science makes claims about what is actual, but not about either what is necessarily the case or what is merely possible. (3) Metaphysics, by contrast, makes claims about possibilities. (4) But 'only if we can delimit the scope of the possible can we hope to determine empirically what is actual'. (5) So those metaphysical assumptions 'go beyond anything science can legitimize'.

I have two comments about premise (2). First, suppose that there are Kripkean a posteriori necessities: statements that are necessarily true but which can be known to be true only a posteriori - perhaps only by scientific inquiry (Kripke (1980), lecture III). Such cases are not, I think, counter-examples to Lowe's claim (though see $\S 5$ below). Science says, of many such statements, whether they are true. Science does not say, of any such statement, whether it is necessarily true or not. Philosophical analysis says, of any such statement, that it is necessarily true if true. So, if philosophical analysis says of some statement $S$ that $S$ is necessarily true if true, and science says that $S$ is true, we can conclude that $S$ is necessarily true. We could not have known that $S$ is necessarily true unless science said that $S$ is true. Yet science itself does not say that $S$ is necessarily true.

Second, there is a better ground on which to challenge premise (2). Physics specifies laws of nature and mechanisms that tell us much about what is not actually the case but is still physically possible. The same laws and mechanisms also tell us much about what is physically necessary. This is modal information that is not information about what is only actually the case. In addition, this is not information that metaphysics in Lowe's sense can provide, since Lowe takes metaphysics to be an a priori activity and we cannot know a priori what is physically possible. But since what is (merely) physically possible is (merely) metaphysically possible, science can provide us with knowledge of what is metaphysically possible but not actual, contrary to premise (2).

I also query premise (4) of Lowe's argument on several grounds. First, suppose that science tells us that $p$. Modal logic tells us that if $p$ then possibly $p$. We can then conclude that possibly $p$. Metaphysics is not needed to determine that possibly $p$ is true. Second, it would be absurd to suppose that, for any claim that science makes, metaphysics is needed to show that that claim is possibly true. For instance, science claims that each proton is composed of three valence quarks. In so far as we have a high degree of belief that it is metaphysically possible that each proton is composed of three valence quarks, it is just because we have a high 
degree of belief both that each proton is composed of three valence quarks and that the above principle of modal logic holds. So it is not the case that we have to work out, via metaphysics, what is possible ('the scope of the possible') and only then can we work out what is actual. As we've seen, in some cases the converse holds. The principle Lowe is apparently relying on is this:

If $p$ presupposes $q$, then to know whether $p$, we need to tell whether $q$ independently of knowing whether $p$.

This principle faces counter-examples. That the rose is red presupposes that the rose has a colour. But there is no way to tell whether the rose has a colour independently of telling whether the rose is red.

Lowe's talk of 'delimiting the scope of the possible' suggests that we need to survey the totality of non-modal claims and determine which claims are possibly true before we can determine which claims are actually true. That is not the case. It is reasonable to have some beliefs about what is actually the case whilst being agnostic about many claims about what is possibly the case. For instance, it is reasonable to be confident that one has hands even if one is agnostic about (say) whether it is possible that there is a lump of transparent iron.

Again, Lowe writes that:

... although what is actual must for that very reason be possible, experience alone cannot determine what is actual, in the absence of a metaphysical delimitation of the possible (Lowe (1998), p. 9).

That passage has an impressive Kantian ring to it, yet what it says cannot be correct. Experience tells us about the world but it cannot have to wait upon metaphysicians to say what is possible and what isn't. Metaphysicans have never determined the extent of what is possible - what all and only the metaphysical possibilities are. No matter. Our senses can give us reason to believe that our train is pulling into the station even if metaphysicians have not yet shown us that is possible that our train is pulling in - and even if Zeno has tried to show that it is impossible for the train to do this.

Perhaps Lowe is not to be understood as holding out for a temporally prior delimitation of the scope of the possible: working out what is possible before working out what is actual. Instead, the metaphysical delimitation of the possible is to be done in tandem with scientists working out what is actual. I think, however, that much the same charge arises: there is no need for metaphysicians to work out what is possible independently of what scientists are trying to work is actual. Empirical reason to believe that $p$ provides reason to believe that $p$ is possible (given the above modal principle that takes us from actuality to possibility). So there is 
no call for metaphysical efforts to establish possibly $p$ in any case in which we have overall empirical reason to believe that $p$. That would be wasted effort. But then there is no work for Lowe's metaphysics to do here.

I have taken Lowe to be claiming that we know that $p$ only if (independently of our knowing that $p$ ) we know that $p$ is possible. Suppose instead we were to take Lowe to be claiming that we know that $p$ only if we can explain why $p$ is possible. On this reading, 'a metaphysical delimitation of the possible' is an explanation of why $p$ is metaphysically possible, for every metaphysical possibility $p$. If Lowe's claim is understood this way, it is not open to counter-examples such as the red rose. But it is open to at least one of my other objections. Our senses can give us reason to believe that our train is pulling into the station even if metaphysicians have not yet shown us that it is possible that our train is pulling in, and a fortiori they have not shown why it is possible that the train is pulling in. Moreover, it is hard to see how every metaphysical possibility could be explained. Explaining why $p$ is possible requires that there is some $q$ such that $p$ is possible because $q$. But that in turn requires that $q$ is possible. Explaining any possibility will require assuming that something else is possible. So not all possibilities will be explained. It might be conjectured that there is some $r$ such that the expectation of why $r$ is possible is that $r$ is possible. But even if an explanation could have this structure, a yet further possibility is being assumed - namely that it is possible that the explanation of why $r$ is possible is that $r$ is possible - and it is hard to see how that possibility could itself be explained without assuming some other possibility.

Although Lowe claims that 'metaphysics is the systematic exploration of the bounds of possibility' (Lowe (2008), p. 278), in fact he takes metaphysics to lay claim to much more than this. Here is what he says about time:

Physicists offer us their various theories of time and space, but the question of what, if anything, time is is a metaphysical one par excellence. The mere fact that a mathematical theory of physics employs a variable ' $t$ ' whose numerical values are somehow correlated with clockreadings is no guarantee whatever that what those values really signify are times. There is a prior question to be addressed as to the ultimate nature of temporality and whether, indeed, there are even such entities as 'times' (Lowe (2008), p. 278, his emphases).

I have some comments on this passage. First, it is not clear what Lowe takes physical theories of time (or better: space-time) to be about, if they are not theories about what time is. Thermodynamics tells us what temperature is; acoustics tells us what sound waves are; and so on. What is it that Lowe thinks physics tells us about time if it doesn't tell us at least something about what time is? For instance, special relativity tells us that time is geometrically isotropic - geometrically the same in all directions. That tells us something very interesting about time - that is to say, about what time is. Lowe frames the issue as a competition: a question is 
for science to answer or for metaphysics to answer but not both. Yet why not? Why frame the debate in that way? ${ }^{1}$ Here is just one way in which physics is relevant. Saying that there are times seems to presuppose something that special relativity denies: namely, that time is an absolute, observer-independent feature of the world. Here is just one way in which metaphysics is relevant. Even if times exist, there remains a question about what times are. Are times concrete sums of events or spatial points? Or are they abstract states of affairs: ways the world was, is or will be? We need to pursue both physics and metaphysics to say what time is.

Lowe has a view about special relativity:

Einstein's theory makes certain fundamental claims about time - for instance, that simultaneity is relative and that the velocity of light cannot be surpassed - but that it does indeed concern time, and that in having such a concern it concerns something whose reality is possible, are metaphysical questions which no merely scientific theory of this sort can settle (Lowe (1998), p. 13).

Here Lowe is conceding that special relativity is about time - and thereby that it tells us something about what time is - but he places two preconditions on its doing so, preconditions that, he says, only metaphysics can meet. The first is whether special relativity 'does indeed concern time'. But why should there be any issue here about whether it does? Why should there be any issue here if there isn't a special issue about whether thermodynamics concerns temperature and acoustics concerns waves? And how would admitting an ontological category of time, which it is the privilege of metaphysics to investigate, settle the issue of whether special relativity is about time? How would that settle the question of how special relativity is to be interpreted? For that matter, how would the admission of an ontological category of time settle the interpretation of a metaphysical theory apparently about time?

The second precondition that Lowe mentions is that special relativity concerns something whose reality is possible. But, to repeat a line of argument already mentioned, evidence that special relativity concerns something actual is thereby evidence that it concerns something possible. So I don't see that there is a case for insisting that metaphysics has to perform some prior modal task, namely investigating the possibility of time, before physics can be given the 'all clear' and allowed to investigate time.

Recall that Quine seeks to say what there is by appeal to what a regimented version of today's science quantifies over. Suppose that our regimentation quanti-

1 For a case that itemizing ontological categories is an empirical matter, see MacBride and Janssen-Lauret (2015). 
fies over numerical values correlated with clock-readings. Of course such a sparse description does not guarantee that our regimentation quantifies over times; perhaps our regimentation is quantifying over the values of some quantity that increases over time - such as steam from a kettle on the boil. To get anything more in the way of a guarantee, we need to look at what else the theory has to say about those values. Times, whatever else they are, are things that occupy a certain roleas minimal regions of space-time. Whether the values of the variables of our regimented theory deserve to be called 'times' then depends upon whether they occupy that role (fully or near enough). ${ }^{2}$ There is also an ambiguity in Lowe's charge. If the issue is about the interpretation of scientific theory - what the theory takes ' $t$ ' to range over, whether or not there are any such entities - there is no special problem facing the interpretation of this scientific theory as opposed to any other. If the issue is, on the other hand, whether or not there are such entities, then to say, as Lowe does, that 'there is a prior question to be addressed as to the ultimate nature of temporality' is simply to reiterate a claim we have addressed - the claim that science cannot say what time is and that this is a task that falls to metaphysics alone.

I conclude that Lowe's case against science as a means of doing metaphysics fails.

It is worth noting that there are two distinguishable elements to Quine's metaphilosophy. There is his doctrine of ontological commitment: that what exists is what is quantified over by a regimentation of a true theory, itself understood as a set of sentences. But Quine also has a view about what provides true theory; namely, that it is provided by science and science alone. It is open for us to accept Quine's doctrine of ontological commitment but not his austere view of what is the source of true sentences. That is, it is open for us to say that it is not just science that provides true sentences to which the doctrine of ontological commitment is to be applied. We have good reason to believe claims in addition to those that science makes, namely claims that we ordinarily make about ourselves and

2 Lowe's complaint that no guarantee has been provided seems out of place with the fallibilism that he elsewhere advocates:

We should not expect metaphysics to be able to produce such final solutions, any more than we should expect them in mathematics or any other intellectual discipline. It was, indeed, Kant's unreasonable expectation that we should be able to arrive at certainty in metaphysics that led him to distort it into an examination of the structure and content of our thought about reality rather than of the structure and content of reality itself (Lowe (2008), p. 277. See also Lowe (1998), pp. 24 and 27, and Lowe (2011), p. 104). 
our surroundings in the traffic of day-to-day life (Chisholm (1976), chapter 1 §2). This enhanced body of truths - science plus common sense - holds up as well as a source of information for metaphysics as Quine's more meager data base

\section{Lowe's case against semantics usurping metaphysics}

Lowe also argues against the suitability of semantics to answer metaphysical questions. Lowe's chief target is a view held by Michael Dummett, amongst others, according to which 'metaphysical questions can in principle be resolved by recourse to (and only by recourse to) the theory of meaning' (Lowe (1998), p. 17, his emphases). This is not Quine's view since he eschews the theory of meaning. But there is enough commonality between Quine and Dummett's view: both seek to address metaphysical problems by the method of paraphrase (at least as understood as explication: Quine (1960), §53) and the assignment of truth conditions to sentences in accordance with bivalence and the choice of a canonical notation (Quine (1981), p. 32).

Lowe's first charge is that this approach 'threatens to reduce metaphysics to something even more parochial, by making answers to its questions turn on the linguistic practices of an arbitrarily chosen human community' (Lowe (1998), p. 17). I think this charge is misguided. There is only one human community, humankind, so it can hardly be arbitrarily chosen. Perhaps, however, Lowe has in mind a particular human sub-community: the community of English speakers. It would be arbitrary to single out this sub-community but, if this is Lowe's charge, it misses the mark. Quine's approach does not privilege any one natural language. Quine's canonical language is first order logic; its predicates are drawn from scientific theory with no favour for any particular natural language in which that theory is expressed. Of course the linguistic practices of any group of speakers could have been different. But then, more generally, the cognitive resources of any group of thinkers could have been different. Does that make the answers to metaphysical questions turn on the intellectual practices of an arbitrarily chosen human community? If it does, does that matter? And if it does not matter, it is unclear what it is the force of Lowe's charge against specifically linguistic practices.

Second, Lowe reports that 'the basic problem' with the appeal to semantics is that:

to the extent that one can legitimately appeal to considerations of meaning in order to answer metaphysical questions, the considerations in question must not be merely ones of 
what we do mean - for there is no guarantee that we mean anything very precise or coherent by what we say - but, rather, they must be considerations of what we should mean. This is to reiterate the point that metaphysics must be critical and potentially revisionary of our currently accepted concepts and beliefs. However, questions of what we should mean cannot be answered wholly from within the theory of meaning, but require recourse to independent metaphysical argument (Lowe (1998), p. 17. See also Lowe (2012), p. 924).

I have two points to make in reply. First, if the defence in $\S 2$ of the role of science in metaphysics is successful, the theory of meaning can be complemented with information from scientific theories and findings to guide us to what we should mean. The charge made in the above passage is then a red herring.

Second, we have to distinguish between where we are and where we want to get to. Where we want to get to is to be in a position where we have concepts and words that characterize what there is in illuminating and explanatory ways. Perhaps some, perhaps even many, ingredients of our current stock of concepts and words - our ideology, in Quine's sense - fail to do this. But we have to work with what we've got. It does not follow that questions of what we should mean cannot be answered within semantics. Likewise, we want to get to be in a position of having true beliefs and no false beliefs: we want to be in a position where the only beliefs we have are beliefs that we should have. But to get to that position we have to work with the beliefs that we already have.

What goes for beliefs in general goes for metaphysical beliefs in particular. There are the metaphysical beliefs that we have and there are those we should have. Presumably Lowe would not think that questions of what metaphysical beliefs we should have cannot be answered wholly from within metaphysics but requires recourse to work from some independent discipline. But if that is so, it is hard to see why Lowe thinks he has a better case against semantics.

Lowe illustrates his case by considering the notion of an object (Lowe (1998), p. 8). Suppose we say that an object is whatever is the referent of a singular term or the referent of some possible singular term. Lowe's riposte is that this is too permissive: he claims that there are expressions which qualify as singular terms but which do not refer to an object of any sort. But even if this is correct, it is not an objection to the suggestion. The suggestion was not that every singular term refers to some or other object. The suggestion was that every object is referred to by some (possible) singular term. That allows that there are empty singular terms.

Lowe offers as an example of a singular term the definite descriptive phrase 'the grin on John's face'. Now, either we say that that phrase refers or it does not. If we say that it does not refer, then there is no counterexample to the proposal in question. If we say that it does refer, then Lowe needs to say why its referent should not be regarded as an object. Perhaps he would say that it is a metaphysical truth 
about objects, properly so-called, that they cannot have intermittent existence, coming, going and coming back again into existence, in the way that smiles or moods do. So be it. But it is open for his opponent to take this to be something delivered by semantics from an analysis of the term 'object'. Or perhaps Lowe is not so much concerned with objects in general but with those objects that he calls substances, where 'a substance might be defined to be an object which does not depend for its existence upon any other object (where dependency is defined in terms of necessity)' (Lowe (1998), p. 10). Whatever 'the grin on John's face' refers to, it does not refer to a substance as so defined, although it would still refer to some other kind of object. But then Lowe's use of the example against his opponent is blocked.

His opponent can go further and maintain that we can substantiate the supposed distinction between genuine objects and such (putative) things as grins by appeal to paraphrase. A sentence such as 'John is wearing a broad grin', which appears to quantify over grins, can be paraphrased as 'John is grinning broadly', which does not quantify over grins. Lowe replies to this that paraphrase is a symmetric relation and that there are 'no resources wholly within the theory of meaning of the language' to settle which of these sentences describes matters accurately and that independent metaphysical argument is called for (Lowe (1998), p. 8). But the symmetry of paraphrase is not a fatal objection to this endeavour. One sentence apparently quantifies over grins. The other sentence does not quantify over them. Since the first sentence is paraphrasable as the second, what we learn is that the first sentence does not quantify over grins. It only apparently quantifies over grins. More generally, wherever there a sentence $S$ which apparently entails $\exists x F x$, and there is some other sentence $S^{\star}$ which does not entail $\exists x F x$, and $S$ is paraphrasable as $S^{\star}$, then there is reason to believe that $S$ does not entail $\exists x F \chi$ and only apparently does so (Keller (2017), §3).

I conclude that Lowe's case against semantics and philosophical analysis as a means of doing metaphysics fails.

\section{Lowe on metaphysics as the study of the fundamental}

So much for Lowe's criticisms of the Quinean view of metaphysics. I now turn to his own view. Lowe says that metaphysics investigates fundamental structures and categories and thereby discovers what is metaphysically possible. It is the 'science of essence' (Lowe (2011), pp. 99-100).

Our first question is: what is a fundamental structure or category? Let's first 
consider what metaphysical possibility is. Lowe operates with a threefold distinction between (a) strict logical possibility (that which is consistent with the laws of logic), (b) conceptual possibility (or narrowly logical possibility: that which is consistent with the laws of logic together with definitions of non-logical terms), and (c) metaphysical possibility (or broadly logical possibility: that which obtains in some world in which the laws of logic hold true) (Lowe (1998), p. 14). His thinking is that it is strictly logically possible that something is red and green all over at the same time and that it is conceptually possible, but that it is not metaphysically possible (Lowe (2012), p. 920). There are no metaphysically possible worlds in which something is red and green all over at the same time. But which worlds are at issue? If they are only the physically possible worlds (worlds with the same laws of nature as the actual world), then the range of worlds is too restricted - at least by Lowe's lights. ${ }^{3}$ (And since it is for science to say which worlds are physically possible, it would then be for science to say which worlds are metaphysically possible. That would be an unwelcome result for Lowe). If the worlds at issue are the metaphysically possible worlds, we have either appealed to the same notion that we wanted light shed on - metaphysical necessity - or we have to say that they are worlds with the same laws of metaphysics as the actual world. ${ }^{4}$ This only raises the question of what the laws of metaphysics are - a task no more tractable than saying what metaphysics is on Lowe's view. What, after all, distinguishes a law of metaphysics from a law of physics? That seems no easier to answer than saying what distinguishes metaphysics from physics.

Next, what is a fundamental structure or category? These are 'the basic varieties or types of entities, a catalogue of which is indispensable for the purpose of characterizing the fundamental structure of reality as a whole' (Lowe (2008), p. 282). Lowe comments that metaphysical questions are 'questions more fundamental than any that can be competently addressed by empirical science' (Lowe (1998), p. 9). Whatever else it does, that comment cannot be used to specify what he means by 'fundamental' because it simply rules out, by definition, the possibility that science answers metaphysical questions. As Lowe recognizes, whether science can answer such questions is something that needs to be argued for and

3 For an opposing view to Lowe's on this point, see Edgington (2004).

4 Lowe writes that:

the validity of a claim that a certain state of affairs is metaphysically possible does not simply hinge on the question of whether or not the propositions used to describe it entails a contradiction, but rather on the question of whether acceptable metaphysical principles and categories permit the existence of that state of affairs (Lowe (1998), p. 12). 
cannot be simply assumed at the outset of debate.

Lowe further argues that:

... metaphysics is the study of the most fundamental structure of reality as a whole. As I see it, metaphysics is needed in this role because truth is single and indivisible, but other disciplines pursue it only within delimited domains [footnote omitted]. Because other disciplines pursue truth only within delimited domains, no one of these other disciplines is equipped to adjudicate between the potentially conflicting truth-claims of their various practitioners. To give an obvious example: theological truth-claims may threaten to conflict with the truth-claims of physical scientists. Since truth is single and indivisible, a resolution must be sought, but neither physical scientists nor theologians as such are equipped to seek, much less to find, it. If a resolution can be found at all, it will be found in metaphysics (Lowe (2008), p. 278, his emphases. See Lowe (2011), p. 104).

The above argument fails. First, by Lowe's own reckoning, metaphysics is distinct from science, and so metaphysics has a delimited domain. Not everything that can be studied can be studied by metaphysics. So metaphysics is no better than physics in that it pursues truth only within a delimited domain. If that is enough to disqualify physics from resolving potentially conflicting truth-claims drawn from their different disciplines, it is also enough to disqualify metaphysics.

Second, we have historical examples of conflicting truth-claims drawn from different disciplines but where the resolution of these conflicts did not call for metaphysics but for better science. For example, there was the nineteenth century conflict between Lord Kelvin and the geologists of his day about the age of the Earth. (For details, see Burchfield (1975)).

Third, even if metaphysics can mediate between different disciplines when they make conflicting truth-claims, it is unclear how it follows from that that 'metaphysics is the study of the most fundamental structure of reality as a whole'. Where truth-claims conflict because it is apparently logically or conceptually impossible for them to be jointly true, it falls to logic or philosophical analysis to settle whether or not this is a genuine logical or conceptual impossibility. And, according to Lowe, logic and philosophical analysis are distinct from metaphysics. So there is no call for metaphysics from that quarter. And even if truth-claims conflict because it is apparently metaphysically impossible for them to be true, we do not need to establish what is metaphysically fundamental in order to settle them. If historians say that the king's ring is made of gold, and chemists say that it is made of iron pyrite, it is metaphysically impossible for them both to be true. But it does not require an investigation into 'the most fundamental structure of reality' to decide between those rival claims. ${ }^{5}$ Lastly, some conflicts between the

5 Lowe would presumably reject this example as misguided: he claims that, unlike natural kinds 
truth-claims of different disciplines do not concern any kind of possibility. The claims of one discipline may make the claims of another discipline improbable. For instance, it has been alleged that claims made by evolutionary biology make improbable various claims that theism makes (Draper (2008)). However such disputes are to be settled, they are not settled simply by showing that it is metaphysically possible for the conjunction of such claims to be true. But if that is all that Lowe's form of metaphysics can achieve, then it is not adequate to the task.

Lowe denies that ontological categories are entities and he does not want to say that ontological categories exist (Lowe (2004), p. 307 and Lowe (2008), p. 281). (Nor does he want to say that they do not exist). His motivation for saying this is given by the following argument: (1) Lowe has an ontology with exactly four fundamental ontological categories. ${ }^{6}$ (2) If he admitted the existence of fundamental ontological categories, he would have to admit the existence of four fundamental ontological categories plus the existence of a fifth fundamental ontological category, that of being an ontological category. (3) But that claim is 'absurd' - it contradicts (1). (4) So fundamental ontological categories do not exist (Lowe (2008), pp. 281-282).

The obvious response to this argument, however, is to deny premise (1) and so reject premise (3). What premise (2) tells us is that Lowe miscounted the num-

such as gold, ontological categories are knowable a priori (Lowe (1998), p. 16). As I think that, strictly speaking, it is statements that are knowable a priori or knowable $a$ posteriori, I take this to be an elliptical way of talking about certain statements about ontological categories (as opposed to natural kinds) are knowable $a$ priori. But Lowe needs to provide an argument for thinking that any such statements about ontological categories are knowable a priori. It is not knowable a priori that Missy the cat belongs to the ontological category object, since you do not know a priori that Missy the cat exists. And if we say that it is knowable a priori that if Missy the cat exists, then Missy belongs to the ontological category object, then the contrast with natural kinds is lost, for it is knowable a priori that if Missy the cat exists, then Missy belongs to the biological category mammal. There is the option of saying that relations between ontological categories are knowable $a$ priori, so that, for instance, it is knowable a priori that it is metaphysically possible that some particular is not a substance, or that it is knowable a priori that it is metaphysically possible that some entities are kinds. The trouble is that, even if we grant this, it is very hard to see how knowledge of this sort can warrant any of the quite specific claims that would be needed to 'delimit the scope of the possible'. How, for instance, would a priori knowledge of relations between ontological categories warrant claiming that it is metaphysically possible that metals conduct electricity? I don't even see how a priori knowledge of relations between ontological categories warrant claiming (as Lowe does) that if something belongs to a given ontological category then it could not have belonging to a different ontological category. A priori knowledge of relations between ontological categories seems too impoverished to provide the wealth of modal knowledge that Lowe regards as a precondition for having any knowledge of actuality.

6 Namely, (1) objects, (2) kinds, (3) properties and relations and (4) modes. 
ber of fundamental ontological categories that he had; his conviction that he accepted exactly four was mistaken. In any case I am puzzled by Lowe's view in two respects. First, Lowe is prepared to say that there are exactly four fundamental ontological categories. How does quantification interact with claims about entities? On Lowe's view, it is the case that there are exactly four fundamental ontological categories and it is not the case that there are exactly four entities that are fundamental ontological categories. I do not understand how that claim could be true. Second, how does quantification interact with existence claims? On Lowe's view, there are exactly four fundamental ontological categories but it is not the case that there exist exactly four fundamental ontological categories. I do not understand how that claim could be true. There is an option of adopting a neo-Meinongian semantics (as endorsed by, for example, Crane (2013), pp. 34-42) but at least in print Lowe was silent on this issue.

We can press these points further. Consider the analysis of the adjectival occurrence of a numeral in terms of quantification and identity, i.e. that to say there are four $F$ s is to say that there is an $F$, another $F$, etc. and that each of these $F \mathrm{~s}$ is distinct. ${ }^{7}$ Lowe might seek to block this by offering another theory of numerical adjectives, but it is not obvious what this theory would say. Alternatively, Lowe can retain the usual analysis of expressions of the form 'four Fs' in terms of first order logic, but then it looks as though he will have to end up saying that the occurrences of the predicate ' $F$ ' in the analysans are expressions of our language which play a certain role in our theory but for which there is no corresponding ontology. But, by taking this route, Lowe would be following Quine in endorsing a distinction between ideology and ontology, and it would then be difficult for him to maintain that semantics plays no role in his metaphysics.

The problems here are not alleviated by reconstruing fundamental ontological categories as pluralities of the elements that the categories putatively apply to. Given that Lowe denies that such categories exist and yet is reluctant to say that they do not exist, he should then deny that the pluralities that such categories are to be construed in terms of exist and be reluctant to say that they do not exist.

By denying that ontological categories exist, Lowe's view is indistinguishable from someone who denies that there are ontological categories (neo-Meinongianism aside). That is the view of the error theorist about ontological categories: the per-

7 More fully, 'there are exactly four Fs' is to be analysed as:

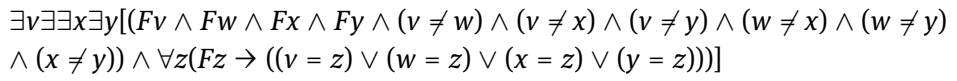


son who denies that the phrase 'the basic varieties or types of entities' refers to anything and who denies that any atomic sentence using that phrase is nonvacuously true. Lowe resists this challenge:

\begin{abstract}
Does this mean that no ontological system can have a realist foundation? Does it mean that ontological categorization is all just a matter of how we choose to classify and describe things - of how we choose to 'carve up' reality, to use the rebarbative metaphor so often favoured by antirealists? Not at all. The difference between, say, an object and a property, or between an object and a mode, is as fundamental, objective and real as any difference could possibly be. Such differences do not rest purely on our ways of describing or conceiving of things ... (Lowe (2004), p. 307).
\end{abstract}

I draw a different lesson from this passage: that the notion of an ontological category does no work. There is no call to say that objects and modes belong to different ontological categories. It's enough to say that (necessarily) no objects are modes. Moreover, saying that does not entail that the difference between objects and modes turns on how we describe the things to which we apply these terms, anymore than the difference between chalk and cheese turns on how we happen to describe them. Lowe complains that Quine does not allow for any 'categorial differentiations amongst 'things' in any ontologically serious sense' and that the only sense in which Quine allows that things differ is that different predicates are true of them (Lowe (2006), p. 196). It is unclear to me what the first complaint amounts to and the second complaint misreads Quine. For consider: Quine says that various barns, sunsets and houses are each red but that 'all of them are red may be taken as ultimate and irreducible' (Quine (1948), p. 30). A fortiori, that all of them are red is not, contrary to Lowe's interpretation of Quine, to be explained by the term 'red' applying to each of them. Corresponding remarks apply to all other cases - chalk and cheese (or, to use Lowe's example) kings and cabbages.

Quine quipped that 'ontology recapitulates philology' (Quine (1960), p. viii). This does invite the suggestion that so-called ontological categories are projections of linguistic categories: that the category of object is a projection of the category of singular term, the category of property is a projection of the category of predicate, and the category of state of affairs is a projection of the category of declarative sentence. This suggestion is unwelcome to Lowe. In his eyes it would make metaphysics 'parochial' and subject to 'the linguistic practices of an arbitrarily chosen human community' (Lowe (1998), p. 7). He seeks to counter this by claiming that 'any language which has evolved as a means [of] expressing truths about reality must embody some recognition, however partial and distorted, of the metaphysical categories in terms of which the fundamental structure of reality is to be articulated' (Lowe (1998), pp. 10-11). That is a remarkable claim. Consider the parallel in the case of physics: that any language which has evolved as 
a means of expressing truths about reality must embody some recognition, however partial and distorted, of the fermions and bosons which (supposedly) form the physically fundamental structure of reality. That claim looks very improbable. What makes Lowe's claim about metaphysics any more probable? If it is an empirical claim, no evidence is presented for it; if it is an a priori claim, no argument is given for it. And it is all the more surprising that Lowe should make it given that he also says that 'our natural beliefs are products of evolutionary processes which are geared to the practical demands of survival rather than to the theoretical demands of metaphysical truth' (Lowe (1998), p. 7). Lowe issues a protest: 'Let us not lose sight of the fact that there can be major disputes amongst genuine ontologists who speak the same language - something that could hardly be the case if categorial systems were fixed in our brains as a product of language' (Lowe (2008), p. 282). But the fact is that such disputes could arise even under those circumstances. They would arise if the disputants were under the misconception that their ontologies marked distinctions in nature and were not projections from the structure of their languages. ${ }^{8}$

\section{Lowe on essences as the ground of possibility}

Lowe claims that essence is the 'ultimate ground of all possibility', since something's essence determines what is necessary and what is possible for it, and that metaphysics needs to study the essences of things in order to get knowledge of possibility (Lowe (2008), p. 278, and Lowe (2012), p. 939). So, for instance, it is part of the essence of a substance that it is a substance, 'as a consequence of which it could not have been something belonging to another ontological category' (Lowe (2008), p. 278). Given what Lowe has to say about ontological categories, it is no surprise that he denies that an entity's essence is some further entity that is somehow related to it. He denies it because he fears a regress: if an essence is an entity, such as a property of a substance, then it too will have an essence, and that essence in turn will have an essence, and so on (Lowe (2008), p. 284, and Lowe (2012), p. 941). I think that either this regress is not vicious or that Lowe will also have to deny that properties are entities. For presumably each property (and each relation) has some property or other, and this too generates a regress. ${ }^{9}$ But if there

8 See in this connection Stove (1991), chapter 7, 'What is Wrong with Our Thoughts? A NeoPositivist Credo'.

9 Is the regress blocked by assuming a sparse theory of properties, whereby the fact that the general term ' $F$ ' correctly applies to something does not $a$ priori entail that there is a property of 
are no properties or relations, then nothing belongs to one of Lowe's four fundamental ontological categories: the category of properties and relations. Denying that essences are entities, however, comes at a cost. Puzzles arise which are analogous to the ones that arise when Lowe denies that ontological categories exist. For instance, Lowe is presumably prepared to quantify over essences ('some essences are better understood than others') and to make singular reference to them ('the essence of a cat is not the same as the essence of a dog'). And again, by denying that ontological categories exist, Lowe's position becomes indistinguishable from that of someone who denies that there are essences. Perhaps his idea is to take the concept of an essence to be a primitive non-referring concept. That still leaves me at a loss as to how we are to understand apparent quantification over and singular reference to essences.

Lowe also has an epistemological argument against essences being entities:

If essences were entities of a special sort, then indeed our grasp of them would be difficult or worse, impossible - to explain. We certainly couldn't know them by some peculiar kind of perception or observation, since any such mental act with intentional content requires a grasp or understanding of that content by its subject and thereby a grasp of the essences of its intentional objects (Lowe (2008), p. 284).

But if taking essences to be entities would make knowledge of them difficult, taking essences not to be entities would not thereby make knowledge of them any easier. ${ }^{10}$ Lowe has this to say about the epistemology of essences:

For it is part of our essence, as thinking beings, that we can grasp the essences of at least some things and thereby understand at least in part what is possible for those things, since what is possible for them is grounded in their essences (Lowe (2008), p. 284).

Lowe goes on to claim that to think of something requires knowing what it is - 'In

being $F$ that something has? No. A sparse theory of properties denies that we can know a priori that every property has a property, but it otherwise leaves it open whether every property has a property. In any case the option of adopting a sparse theory of properties is not available to Lowe. To see this, consider one of his own examples: 'Socrates's property of being the sole member of the set singleton Socrates' (Lowe (2012), p. 934). Call this property $F$. From Lowe's example, we can extract the principle that for any entity $x, x$ has the property of being the sole member of the set singleton $x$. Then $F$ has the property of being the sole member of the set singleton $F$. Call this further property $G$. The regress is now evident.

10 In any case Lowe's argument is unpersuasive. If successful, the most it would show is that not all knowledge of essences is perceptual or observational. If our knowledge of the content of our thoughts, and of the essences of our thoughts, is not perceptual, that leaves open whether our knowledge of the essences of other kinds of thing is perceptual. 
order to think comprehendingly about something, I surely need to know what it is that I am thinking about' (Lowe (2012), p. 944) - and that in turn means knowing what its essence is. It follows that, since we do think about some things, we do know the essences of some things. We know such essences by 'the faculty of understanding, which we exercise whenever we engage in processes of reasoning or reflection' (Lowe (2008), p. 284). His opponent, however, will deny the first premise. We can think of things by means of, amongst other things, demonstrative thoughts. And there is a sense of 'seeing' (non-epistemic seeing) in which one can see a cat, and have thoughts about what one sees, without thinking that it is a cat. ${ }^{11}$ When I then think to myself 'What is that?' I am thinking of that thing without knowing what it is. After all, that is why I ask myself the question. Yet on Lowe's view that is an impossible situation: you could never wonder what something is. By thinking of it, you thereby know what it is. It is then puzzling why there should ever be any disputes about what things are. For Lowe, the essence of something determines its identity conditions and persistence conditions (Lowe (2008), p. 283). Yet disputes about these conditions are standard fare in philosophy. The cost of making knowledge of essence so easy to come by is that it makes the occurrence and persistence of any of these disputes inexplicable. Lowe himself comments that 'it often turns out that our concepts of various really existing kinds of things are seriously inadequate to the true natures of those things' (Lowe (2012), p. 924). The puzzle is how, on his own view, this could ever be the case. The ancient Greeks took stars to be holes in the firmament. How could they have thought about the stars and, despite thinking long about them, continued to misunderstand what they are?

Lowe addresses this kind of challenge in passing when he addresses theories of direct reference. There he comments that:

it does not make sense to suppose that, for successful reference to occur, no one need ever know what it is that they are thinking about. It suffices for my purposes that at least sometimes a thinker must be able to know this (Lowe (2012), p. 944).

And later he adds:

I do not insist that we need fully grasp the whole essence of a thing in order to be able to think about it to some degree adequately (Lowe (2012). p. 946).

Yet the example of the ancient Greeks is precisely an example of people who successfully referred to stars but who never knew what they were thinking about.

11 Dretske (1969), chapter 2. 
They lived and died in ignorance of what stars were. ${ }^{12}$ Far from this not making sense, it is historical fact. For related reasons I would say that Berkeley did not know what physical objects were. And to say that 'it suffices for [Lowe's] purposes that at least sometimes a thinker must be able to know this' is to make a retreat. His opponent can grant that, for the sake of argument, at least sometimes if you refer to something, you must be able to know what you referred to. But it does not follow that you are ever able to know that just by reasoning and reflecting. ${ }^{13}$

The unacknowledged source of Lowe's thinking of these matters is, I conjecture, Aristotle's Posterior Analytics. Aristotle claims that, given an intellectual grasp of something's essence, we can demonstrate its other properties: we can show how its other properties proceed necessarily from its essence. Knowledge of essence is taken to be knowledge of what something is. But what is it to know what something is? In one clear sense it is to know what that thing is like - what properties it has. I know what my pet Missy is. She is a fluffy, ginger and hungry cat. Knowing this, I have enough information to pick Missy out from any of the other things found around the house. But that is not the sense of knowing what something is which Lowe intends. He is interested in what it is to know what something is essentially. According to Lowe, I know something about what Missy essentially is - that she is essentially a cat - and I know that other things about Missy are not essential features of her - that she is not essentially fluffy, ginger and hungry. Very well. But now the question of how we get modal knowledge - knowledge of what is necessarily true and of what is merely possibly true - has been only pushed back a stage. How do we get to know that some feature is essential to a thing and that some other feature is accidental to it? How do I get to know that Missy is essentially a cat and only accidentally ginger? I can reason and reflect of course. But what reflections should I make about Missy? How am I to tell which reflections would track essential features of Missy and which would track accidental features of her? What chains of reasoning should I engage in? And what premises should initiate those chains? Lowe provides no answers to such questions other than to

12 Thinking of the stars as luminous bodies in the night sky would fail to distinguish stars from meteors - so-called shooting stars are not stars.

13 I am also unclear what Lowe's claim amounts to. Presumably he is not claiming that it is a necessary truth that: at some times a thinker must be able to know what she is thinking about whereas at other times she need not be able to know what she is thinking about. I don't see that that is a necessary truth. That aside, I am unclear about the sense of 'must' involved in the claim that you must be able to know what you are thinking about. Lastly, talk of not fully grasping the whole of an essence tends to diminish the interest and clarity of Lowe's thesis. There seems no profit in debating whether or not the ancient Greeks had some grasp of some part of the essence of stars. 
deny that we get knowledge of modality via knowledge of counterfactuals (Lowe (2012)). The utter lack of specificity of Lowe's account leaves the epistemology of essences no more tractable than the epistemology of modality.

We have discussed Lowe's claim that to think of something involves knowing what that thing is and thereby knowing what its essence is. He also comments that it is a frequent feature of metaphysical necessities that they are knowable only a posteriori (Lowe (1998), pp. 15-16). Despite this nod to Kripke and Putnam, I do not see how Lowe can consistently claim all of this. ${ }^{14}$ On his view, essences are the ground of all metaphysical necessity and possibility. He also rejects the view that essences are hidden from us, in Locke's sense (Lowe (2008), p. 284) and he claims that by thinking of something, you can know what its essence is (loc. cit.). On the basis of that claim, we can know a priori the essence of anything we can think about. Now, the way in which essences ground various metaphysical possibilities and necessities also seems to be knowable a priori on Lowe's view (loc cit.).

Given that all metaphysical modality is grounded in essence, we can have knowledge of metaphysical modality, provided we can have knowledge of essence (Lowe (2012), p. 944).

And we get knowledge of which essences ground which metaphysical possibilities and necessities via understanding - via reflection and reasoning. It follows that all of our knowledge of metaphysical possibilities and necessities is knowledge that we can have $a$ priori.

Let's see this with an example. Suppose you have before you a lump of something. What is it a lump of? Well, you can tell what it is just by thinking about it. Having thought about it, you realize that it is, let's say, a lump of gold. What is the essence of gold? You can tell that by thinking too. By reflecting on gold, you can understand what gold is and thereby know its essence. What is involved in knowing something's essence? It enables you to know whatever is necessarily true of that thing and whatever is possibly true of it. But then all your knowledge of the metaphysical possibilities and necessities involving that lump of gold is knowledge that you can have a priori - knowledge you can get by reflecting on what you were thinking about. ${ }^{15}$

14 I set aside the fact that Lowe (2007) expresses scepticism about whether there are necessary truths that are knowable only a posteriori.

15 Lowe has made a logically weaker claim than the ones I cite in the text. He has said: 'And at least in the case of some entities, we must be able to know what they are, because otherwise it would be hard to see how we could know anything at all about them' (Lowe (2012), p. 944). My puzzlement about this claim is why Lowe is prepared to advance it in the case of some entities 


\section{Conclusion}

Seeking to answer metaphysical questions by appeal to science or semantics need not be part of an attempt to disparage metaphysics, as Lowe fears (Lowe (2008), p. 276), nor as something covert, doing metaphysics under the guise of something else, as he also fears (Lowe (2008), pp. 275 and 286-287). Instead, it can be based on the recognition that metaphysics is important but difficult. The tactic deployed in response is to use techniques and information from fields of inquiry that are quite well understood and quite well supported to investigate questions that are intractable and poorly understood. Whether or not it succeeds, or makes better progress than more traditional routes of inquiry into metaphysics, deploying this tactic is good methodology and is not open to the objections that Lowe raises. By contrast, his own view of metaphysics involves both an obscure architectonic of ontological categories that does no useful work and an overambitious appeal to essences that would - absurdly - make all knowledge of what things are, what they could be and what they must be available $a$ priori. ${ }^{16}$

\section{Bibliography}

Burchfield, J. D. (1975), Lord Kelvin and the Age of the Earth, London: Macmillan.

Chisholm, R. M. (1976), Person and Object, London: George Allen and Unwin.

Crane, T. (2013), The Objects of Thought, Oxford: Oxford University Press.

Draper, P. (2008), “Evolution and the Problem of Evil”, in Philosophy of Religion: Philosophy of

Religion, edited by L. P. Pojman and M. Rea, Thomson Wadsworth, Belmont, 5th edition,

207-219.

Dretske, F. I. (1969), Seeing and Knowing, Chicago: University of Chicago Press.

Edgington, D. (2004), "Two Kinds of Possibility", in Proceedings of the Aristotelian Society: 78, $1-22$.

Horvath, J. (2014), “Lowe on Modal Knowledge”, in Thought: 3, 208-217.

Keller, J. A. (2017), "Paraphrase and the Symmetry Objection”, in Australasian Journal of

Philosophy: 95, 365-378.

Kripke, S. (1980), Naming and Necessity, Oxford: Blackwell.

but not all. I do not see why the consideration he raises - 'otherwise it would be hard to see how we could know anything at all about them' - would apply to only some entities if it applies at all. I have pressed worries about the epistemology of essences. There is also a worry about how knowledge of essences, even if we had it, would provide knowledge of modality. For this second worry, see Horvath (2014).

16 I am grateful to the audience at the 2019 Warsaw conference for discussion. I am also grateful to Fraser MacBride for comments on an earlier version of this paper. 
Lowe, E. J. (1998), The Possibility of Metaphysics: Substance, Identity, and Time, Oxford: Oxford University Press.

Lowe, E. J. (2004), "Some Formal Ontological Relations", in Dialectica: 58, 297-316.

Lowe, E. J. (2006), The Four-Category Ontology: A Metaphysical Foundation for Science, Oxford: Oxford University Press.

Lowe, E. J. (2007), "A Problem for A Posteriori Essentialism Concerning Natural Kinds", in Analysis: 67, 286-292.

Lowe, E. J. (2008), "New Directions in Metaphysics and Ontology”, in Axiomatics: 18, 273-288. Lowe, E. J. (2011), “The Rationality of Metaphysics”, in Synthese: 178, 99-109.

Lowe, E. J. (2012), “What is the Source of Our Knowledge of Modal Truths?”, in Mind: 121, 919-950.

MacBride, F. and Janssen-Lauret, F. (2015), “Metaontology, Epistemology, and Essence: On The Empirical Deduction of The Categories", in The Monist: 98, 290-302.

Quine, W. V. O. (1948), “On What There Is", in Review of Metaphysics: 2, 21-38.

Quine, W. V. O. (1960), Word and Object, Massachusetts, Cambridge: MIT Press.

Quine, W. V. O. (1981), “What Price Bivalence?”, in Journal of Philosophy: 78, 90-95.

Stove, D. (1991), The Plato Cult and Other Philosophical Follies, Oxford: Basil Blackwell. 



\section{Authors of Contributed Papers}

Christopher Daly is a Professor of Philosophy at the University of Manchester. His principal research interests are in metaphysics, philosophical methodology, and philosophy of language. He is the author of Introduction to Philosophical Methods (Broadview, 2010) and Philosophy of Language: An Introduction (Bloomsbury, 2012). He has published papers on natural kinds, properties, truthmaker theory, grounding, philosophy of mathematics, and fictionalism. He is an Associate Editor of the Australasian Journal of Philosophy. He and David Liggins are currently directing a research project entitled The Foundations of Ontology, funded by the UK Arts and Humanities Research Council.

Rèognvaldur D. Ingthorsson is an Icelandic philosopher and a Temporary Senior Lecturer at Linköping University, Sweden. Ingthorsson is best known for his work in the metaphysics of time, persistence, causation, powers, and truth, many of which are cited in The Stanford Encyclopedia of Philosophy. However, he has also made excursions into the phenomenology of time, the philosophy of science, and the philosophy of sport. He is the author of McTaggart's Paradox (2016) and $A$ Powerful Particulars View of Causation (2020), and co-editor of Mental Causation and Ontology (2013).

Christian Kanzian is a Professor of Philosophy at the University of Innsbruck, Austria. He is, since 2006, the president of Austrian Ludwig Wittgenstein Society (Österreichische Ludwig Wittgenstein Gesellschaft). Kanzian's main interests are the analytic philosophy, the history of philosophy, and ontology. He is the author of four books: Originalität und Krise - Zur systematischen Rekonstruktion der Frühschriften Kants (1994), Grundproblerne der Analytischen Ontologie (with E. Runggaldier, 1998), Ereignisse und andere Partikularien (2001), Ding - SubstanzPerson. Eine Alltags-ontologie (2009), and an editor or co-editor of eleven books. He has also published over seventy articles.

Markku Keinänen is Adjunct Professor of Theoretical Philosophy at Tampere University, Finland. He studies formal ontology and the metaphysics of science, and he has systematically developed trope theory SNT (Strong Nuclear Theory) in several research articles. Moreover, Keinänen has published on the metaphysics of modality, developed universal bundle theories, and studied E.J. Lowe's metaphysics.

Uwe Meixner is a professor of philosophy at the University of Augsburg, Germany. His main areas of philosophical interest are metaphysics, logic, and philosophical 
theology. He has published four monographs in English: The Two Sides of Being (2004), The Theory of Ontic Modalities (2006), Modelling Metaphysics (2010), and Defending Husserl (2014).

Kevin Mulligan is ordinary professor of philosophy at the University of Italian Switzerland, Lugano; Director of Research, Institute of Philosophical Studies, Faculty of Theology, Lugano; honorary professor of analytic philosophy, Geneva. He has written about analytic metaphysics, the philosophy of mind and the history of Austro-German philosophy from Bolzano to Wittgenstein. He is a member of the Swedish and European Academies.

Peter Simons is Emeritus Professor of Philosophy at Trinity College Dublin. He specialises in metaphysics and ontology, pure and applied; the philosophy of logic and mathematics; and the history of philosophy in Central Europe in the 19th and 20th centuries. He is the author or co-author of 5 books and some 300 articles. He is a member of the British, Irish, European and Polish Academies.

Mirosław Szatkowski is a professor of philosophy at the Warsaw University of Technology, Poland, and the Director of the International Center for Formal Ontology. He earned his PhD in philosophy from Jagiellonian University in Cracow, Poland, and was habilitated at the Ludwig-Maximilians University in Munich, Germany. Szatkowski's main fields of research are: logic, the foundations of mathematics, and formal ontology. In these areas, he has published papers in the following professional journals: Studia Logica, Zeitschrift für mathematische Logik und Grundlagen der Mathematik (Mathematical Logic Quarterly), Archiv für Mathematische Logik und Grundlagenforschung (Archive for Mathematical Logic), Notre Dame Journal of Formal Logic, Journal of Applied Non-Classical Logics, Journal of Logic, Language and Information, and Metaphysica; and in several collective volumes. He has edited five volumes: Ontological Proofs Today (Frankfurt: Ontos Verlag, 2012), Dualistic Ontology of the Human Person (München: Philosophia, 2013), Substantiality ana Causality (Boston/Berlin/Munich: Walter de Gruyter, 2014), God, Truth, and other Enigmas (Boston/Berlin/Munich: Walter de Gruyter, 2015), and Analytically Oriented Thomism (Editiones Scholasticae, 2016).

Peter van Inwagen is an American analytic philosopher and the John Cardinal O'Hara Professor of Philosophy at the University of Notre Dame. He previously taught at Syracuse University and earned his $\mathrm{PhD}$ from the University of Rochester under the direction of Richard Taylor and Keith Lehrer. Van Inwagen is one of the leading figures in contemporary metaphysics, philosophy of religion, and philosophy of action. He has published nine books and over 200 articles on general 
metaphysics, free will, material objects and human persons, philosophy of religion, logic and language. In 2005 Peter van Inwagen was elected to the American Academy of Arts and Sciences, and in 2011 he received the degree Doctor Divinitatis (honoris causa) from the University of St Andrews. 



\section{Person Index}

Burchfield J. D. 20

Chisholm R. M. 20

Crane T. 20

Daly Ch. 1

Draper P. 20

Dretske F. I. 20

Edgington D. 20

Horvath J. 20
Janssen-Lauret F. 21

Keller J. A. 20

Kripke S. 20

Lowe E. J. 21

MacBride F. 21

Quine W. V. 0. 21

Stove D. 21 
